\title{
PENGALIRAN UDARA UNTUK KENYAMANAN TERMAL RUANG KELAS DENGAN METODE SIMULASI COMPUTATIONAL FLUID DYNAMICS
}

\author{
Sahabuddin ${ }^{1}$, Baharuddin Hamzah², Ihsan ${ }^{2}$ \\ 1 Jurusan Arsitektur, Fakultas Teknik, Universitas Muhammadiyah Makassar \\ 2 Jurusan Arsitektur, Fakultas Teknik, Universitas Hasanuddin, Makassar 90245 \\ Email: sahabuddinlatif@yahoo.co.id
}

\begin{abstract}
ABSTRAK
Sirkulasi udara yang baik sangat dibutuhkan pada ruang berventilasi alami untuk mencapai kenyamanan termal, karena dapat mempercepat proses evaporative cooling, pengeluaran panas dan ketersediaan udara segar dalam ruang. Penelitian ini bertujuan mengkaji aliran udara pada Ruang Kelas Gedung Kuliah Bersama Fakultas Teknik Universitas Hasanuddin di Kabupaten Gowa, agar ditemukan rekayasa pengaliran udara yang dapat mempercepat terjadinya proses pengeluaran panas. Penelitian eksperimental ini menggunakan metode simulasi CFD (Computational Fluid Dynamics). Parameter input dalam simulasi diperoleh melalui pengukuran di lapangan berupa dimensi ruang kelas, luas bukaan ventilasi, dan parameter iklim mikro. Rekayasa aliran udara dilakukan terhadap tiga perlakuan yaitu kecepatan udara, luas bukaan, serta modifikasi dari kecepatan udara dan luas bukaan. Analisis dilakukan untuk mengetahui bagian ruang yang mengalami aliran udara tinggi dan rendah serta mengetahui faktor pendukung dan kendala dengan menggunakan perangkat lunak SolidWorks Simulation 2013. Hasil penelitian memperlihatkan bahwa sistem ventilasi eksisting ruang-ruang kelas dapat mendistribusikan pergerakan udara yang nyaman di dalam ruang antara $0.25 \mathrm{~m} / \mathrm{s}$ hingga $1.5 \mathrm{~m} / \mathrm{s}$, pada parameter inlet $1 \mathrm{~m} / \mathrm{s}$ hingga $3 \mathrm{~m} / \mathrm{s}$ dengan kenyamanan ruangan (51.85\%) hingga (85.19\%). Setelah dilakukan perbaikan sistem ventilasi pada ruang kelas, kenyamanan ruang dapat ditingkatkan menjadi (96.30\%) hingga (100\%), dengan rasio luasan bukaan ventilasi (21.60\%) dari luas lantai ruangan, dengan rincian luas bukaan inlet (14.50\%) dan luas bukaan outlet (7.10\%). Disimpulkan bahwa penambahan luas inlet dan outlet dengan rasio yang tepat pada ruang kelas, dapat mengoptimalkan sirkulasi udara. Diharapkan agar jendela kaca mati pada ruang-ruang kelas di buka untuk menambah luas inlet dan penambahan luas bukaan dinding outlet bagian bawah, pintu sebaiknya di tutup pada saat ruang digunakan.
\end{abstract}

\section{Kata Kunci: Aliran udara, Kenyamanan termal, CFD (Computational Fluid Dynamics)}

\section{PENDAHULUAN}

Telah diketahui bahwa kenyamanan termal yang terpenuhi dalam ruang-ruang pada suatu bangunan akan berefek positif pada peningkatan produktivitas kinerja pengguna. Menurut (Mannan, 2007; Sugini, 2004), selayaknya bangunan dapat memberi ruang beraktivitas yang nyaman (termasuk nyaman termal) kepada manusia sebagai penggunanya agar terlindung dari iklim luar yang tidak menguntungkan, sehingga aktivitas dalam bangunan dapat berjalan dengan optimal.
Upaya mencapai kenyamanan pada bangunan di Indonesia yang beriklim tropis lembap dengan karakteristik curah hujan yang tinggi, kelembapan udara yang tinggi (dapat mencapai angka lebih dari $90 \%$ ), suhu udara relatif tinggi (dapat mencapai hingga $38^{\circ} \mathrm{C}$ ), aliran udara sedikit, serta radiasi matahari yang menyengat dan mengganggu, dapat diatasi melalui strategi pendinginan bangunan dengan cara mengatasi pengaruh negatif iklim dan memanfaatkan semaksimal mungkin pengaruh yang menguntungkan (Talarosha, 
2005; Kurnia dkk., 2010; Takahashi, 2005; Lippsmeier, G., 1994).

Menurut Gratia, dkk. (2004), infiltrasi udara dengan sistem ventilasi alami dapat digunakan untuk meningkatkan kenyamanan termal pada ruang-ruang dalam bangunan. Liping, dkk. (2007) berpendapat, untuk mengkompensasi suhu tinggi pada ruangan bisa dengan meningkatkan jangkauan zona kenyamanan netral dengan memberikan kecepatan udara lebih tinggi.

Indrani (2008), mengkaji kinerja ventilasi pada hunian rumah susun Dupak Bangunrejo Surabaya, dengan parameter yang diamati yaitu air flow rate dan air change $(\mathrm{ACH})$ menggunakan program simulasi AILOS. Hasil menunjukkan bahwa desain bukaan perlu memperhatikan luasan inlet dan outlet karena apabila ACH tidak mengalami kenaikan berarti, maka kecepatan udara internal menjadi rendah dan kenyamanan termal tidak terpenuhi.

Baharuddin, dkk. (2012), menyimpulkan bahwa gedung kuliah bersama kampus baru Fakultas Teknik Universitas Hasanuddin yang berlokasi di Kabupaten Gowa, belum memenuhi standar kenyamanan termal akibat tingginya temperatur udara dan tidak adanya aliran udara dalam ruang, terutama pada waktu siang setelah jam 12.00 WITA.

Sebagai tindak lanjut dari penelitian terhadap obyek Gedung Kampus Baru Fakultas Teknik Universitas Hasanuddin yang berlokasi di Kabupaten Gowa, penulis tertarik untuk menganalisis rekayasa pengaliran udara pada ruang kelas Gedung Kuliah Bersama (Class Room) Kampus Baru Fakultas Teknik Universitas Hasanuddin di Gowa, untuk mendapatkan hasil yang dapat memenuhi tuntutan kenyamanan ruang khususnya kenyamanan termal.

Tujuan penelitian ini adalah agar menemukan rekayasa bukaan inlet dan outlet pada Ruang Kelas Gedung Kuliah Bersama (Class Room) Kampus Baru Fakultas Teknik Universitas Hasanuddin Gowa yang dapat mempercepat terjadinya proses pengeluaran panas untuk mencapai kenyamanan termal.

\section{METODE PENELITIAN}

Lokasi penelitian berada pada Kampus Baru Fakultas Teknik Universitas Hasanuddin, terletak di Kecamatan Somba Opu Kabupaten Gowa, tepatnya berada di bekas lokasi Pabrik Kertas Gowa.

Penelitian ini menggunakan metode simulasi CFD (Computational Fluid Dynamics) dengan perangkat lunak SolidWorks 2013 sebagai alat bantu. Dalam program SolidWorks sudah disiapkan fasilitas untuk membuat geometri yaitu SolidWorks CAD yang terintegrasi dengan SolidWorks Flow Simulation sehingga proses pendefinisian material, set domain, boundary condition, meshing hingga output semuanya dapat dilakukan pada satu software, (Sakti, 2013). Langkah kerja pada penelitian ini mula-mula dibuat geometri ruang kelas (RK). Model / geometri RK dibuat dua tipe berdasarkan luasan, kemudian mendefinisikan material fisik dan sifat material fluida yang akan disimulasi, lalu menentukan kondisi batas (domain), boundary conditions dan set goals. Selanjutnya proses meshing akan dilalukan oleh software secara otomatis pada tahap iterasi.

Parameter yang diinput pada proses simulasi merupakan data dari pengukuran lapangan berupa: 1) data geometri ruang terdiri dari gambar dan ukuran ruang kelas, luasan dan letak bukaan ventilasi; 2) variabel yang menjadi titik acuan pengukuran seperti suhu, kelembapan relatif, dan kecepatan udara, diambil dari pengukuran lapangan yang dilakukan selama tiga hari berturut-turut yaitu tanggal 24-26 April 2013.

Ruang kelas (RK) dibagi dalam dua tipe berdasarkan luasan yaitu RK tipe-A $\left(96.75 \mathrm{~m}^{2}\right)$ dan RK tipe-B $\left(63.00 \mathrm{~m}^{2}\right)$. Simulasi tiap ruang kelas di tentukan 27 titik pengukuran untuk di catat parameter hasilnya yang selanjutnya akan dipakai untuk menilai persentase tingkat aliran yang memenuhi standar nyaman. Elevasi titik ukur ditentukan $0.5 \mathrm{~m}$ (mewakili ketinggian kursi orang duduk); $1 \mathrm{~m}$; dan $1.5 \mathrm{~m}$ (mewakili ketinggian dada dan kepala orang berdiri) dari permukaan lantai kelas. Setiap elevasi terdiri dari 9 titik ukur yaitu 3 titik melintang dan 3 titik membujur, lihat Gambar 1.

Sahabuddin, Baharuddin Hamzah, Ihsan - Pengaliran Udara Untuk Kenyamanan Termal Ruang Kelas Dengan Metode Simulasi Computational Fluid Dynamics 

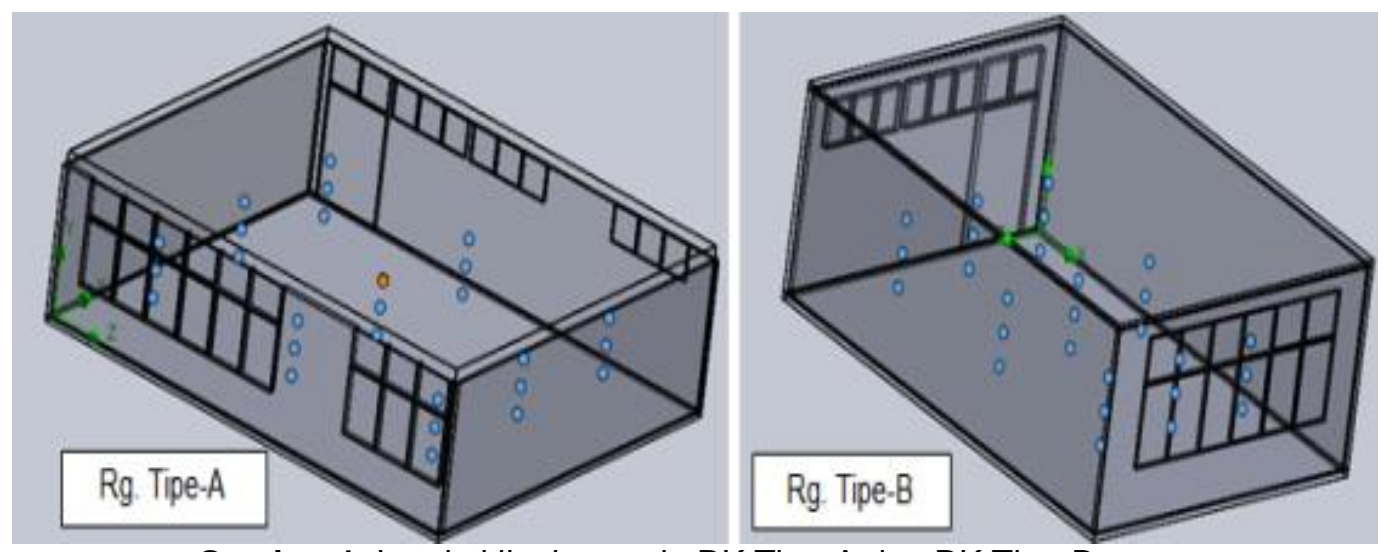

Gambar 1. Letak titik ukur pada RK Tipe-A dan RK Tipe-B

(Sumber: Model simulasi CFD, 2013)

\section{HASIL}

Tingkat aliran udara yang baik ditandai dengan tingginya persentase volume ruang yang memenuhi standar aliran yang nyaman $(0.25 \mathrm{~m} / \mathrm{s}$ hingga $1.5 \mathrm{~m} / \mathrm{s})$, (Lippsmeier G., 1994). Kondisi eksisting RK di dapat kecepatan udara yang memenuhi standar nyaman adalah, RK Tipe-A maksimum (77.78\%) dan RK Tipe-B (85.19\%), diasumsikan RK yang disimulasi dalam keadaan kosong. Rekayasa terhadap luasan bukaan inlet dan outlet RK menghasilkan persentase aliran udara yang memenuhi standar nyaman meningkat menjadi maksimum (100\%) pada RK tipe-A dan maksimum (96.30\%) pada RK tipe-B. Hal ini disebabkan karena luasan inlet dan outlet di perluas hingga mencapai rasio yang ideal dengan penempatan bukaan yang tepat sehingga aliran udara menjadi lancar dengan kecepatan udara yang lebih merata pada seluruh volume ruang yang diinginkan.

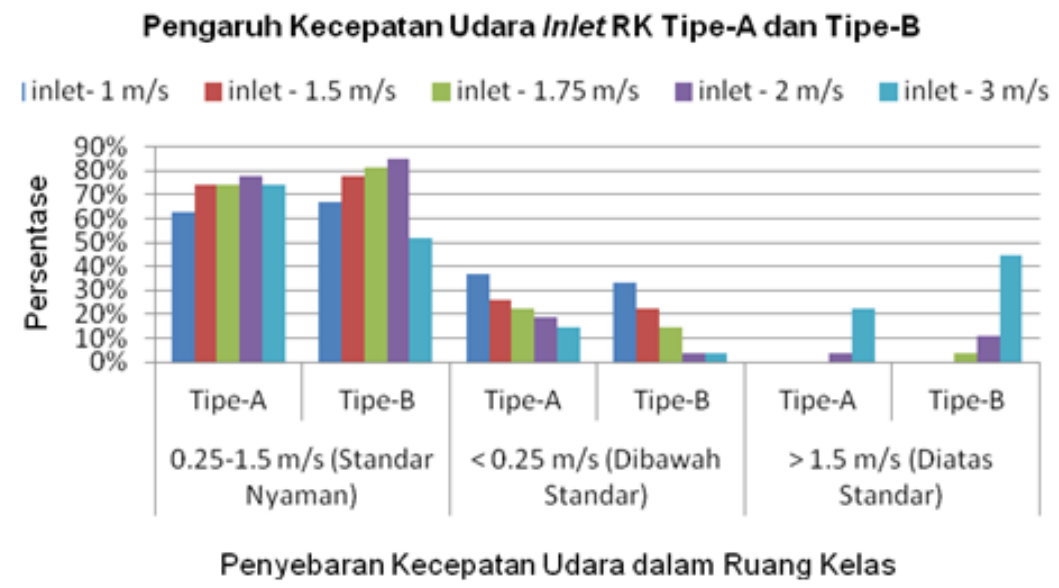

Gambar 2. Grafik Persentase Velocity RK dengan Parameter Velocity Inlet (Sumber: Analisis penelitian, 2013)

Gambar 2, memperlihatkan kecepatan udara yang memenuhi standar kenyamanan termal untuk velocity (kecepatan udara) inlet 1 $\mathrm{m} / \mathrm{s}$ pada RK tipe-A (62.96\%) dan RK tipe-B (66.67\%). Velocity inlet $1.5 \mathrm{~m} / \mathrm{s}$ pada RK tipeA $(74.07 \%)$ dan RK tipe-B $(77.78 \%)$. Velocity inlet $1.75 \mathrm{~m} / \mathrm{s}$ pada RK tipe-A (74.07\%) dan
RK tipe-B (81.48\%). Velocity inlet $2 \mathrm{~m} / \mathrm{s}$ pada RK tipe-A (77.78\%) dan RK tipe-B (85.19\%), sedang untuk velocity inlet $3 \mathrm{~m} / \mathrm{s}$ pada $\mathrm{RK}$ tipeA $(74.07 \%)$ dan RK tipe-B (51.85\%).

Penyebaran kecepatan udara pada RK type-B lebih baik dari RK tipe-A pada velocity inlet $1 \mathrm{~m} / \mathrm{s}, 1.5 \mathrm{~m} / \mathrm{s}, 1.75 \mathrm{~m} / \mathrm{s}$ dan $2 \mathrm{~m} / \mathrm{s}$, 
namun pada velocity inlet $3 \mathrm{~m} / \mathrm{s}$ terjadi sebaliknya. Velocity inlet $2 \mathrm{~m} / \mathrm{s}$ memberikan output pergerakan udara dalam RK lebih baik dibanding besaran kecepatan inlet yang lain. Sehingga dapat dilihat bahwa pada kondisi eksisting, RK tipe-A dan tipe-B dengan kecepatan udara input inlet $1 \mathrm{~m} / \mathrm{s}-3 \mathrm{~m} / \mathrm{s}$ memberikan pergerakan udara yang memenuhi standar kenyamanan termal antara (51.85\% hingga $85.19 \%)$.

Hasil simulasi kondisi existing memperlihatkan bahwa penambahan kecepatan udara inlet hingga $2 \mathrm{~m} / \mathrm{s}$ akan meningkatkan kecepatan udara di dalam RK. Jika kecepatan udara inlet lebih besar dari 2 $\mathrm{m} / \mathrm{s}$ hingga $3 \mathrm{~m} / \mathrm{s}$ maka kecepatan udara yang memenuhi standar kenyamanan akan menurun pada RK, disebabkan meningkatnya persentase kecepatan udara yang melebihi standar kenyamanan. Jika kecepatan udara inlet semakin kecil dari $2 \mathrm{~m} / \mathrm{s}$ hingga $1 \mathrm{~m} / \mathrm{s}$, maka persentase kecepatan udara yang memenuhi standar semakin berkurang yang disebabkan semakin besar persentase kecepatan udara yang kurang dari standar kenyamanan.

Hasil simulasi eksisting juga menjelaskan, jika bukaan inlet dan outlet tidak seimbang maka penambahan kecepatan udara pada inlet tidak serta merta akan meningkatkan kecepatan udara ruangan merata memenuhi standar. Boleh jadi akibat penambahan tersebut mengakibatkan penyebaran kecepatan udara dalam ruang lebih tinggi dari angka standar dan bersamaan dengan itu juga ada aliran udara yang masih dibawah nilai standar yang di harapkan.

Gambar 3, memperlihatkan persentase kecepatan udara dalam RK tipe-A dan tipe-B dengan parameter inlet velocity $1.75 \mathrm{~m} / \mathrm{s}$, dengan suhu dan kelembapan relatif udara dalam RK $\left(31.00^{\circ} \mathrm{C} / 70.97 \%\right)$, dan $\left(30.00^{\circ} \mathrm{C} /\right.$ $64.30 \%$ ) pada inlet di jendela. Berikut urutan bukaan yang paling baik ke paling buruk berturut-turut: bukaan tipe-Z (Gambar 4d), bukaan tipe-X (Gambar 4b), bukaan tipe-Y (Gambar 4c) dan bukaan tipe-W (Gambar 4a). Bukaan tipe-Z dapat mengalirkan udara mencapai (92.59\%) volume ruang yang masuk dalam standar kenyamanan termal $(0.25 \mathrm{~m} / \mathrm{s}$ - $1.5 \mathrm{~m} / \mathrm{s})$ pada RK tipe-B sedangkan RK tipe-A (88.89\%). Persentase volume ruang yang aliran udaranya diatas standar $(>1.5 \mathrm{~m} / \mathrm{s})$ pada RK tipe-A (11.11\%) dan RK tipe-B (3.70\%). Persentase volume ruang yang aliran udaranya dibawah standar $(<0.25 \mathrm{~m} / \mathrm{s})$ pada RK tipe-A $(0.00 \%)$, dan RK tipe-B (3.70\%).

\section{Pengaruh Luasan Ventilasi RK tipe-A dan tipe-B}

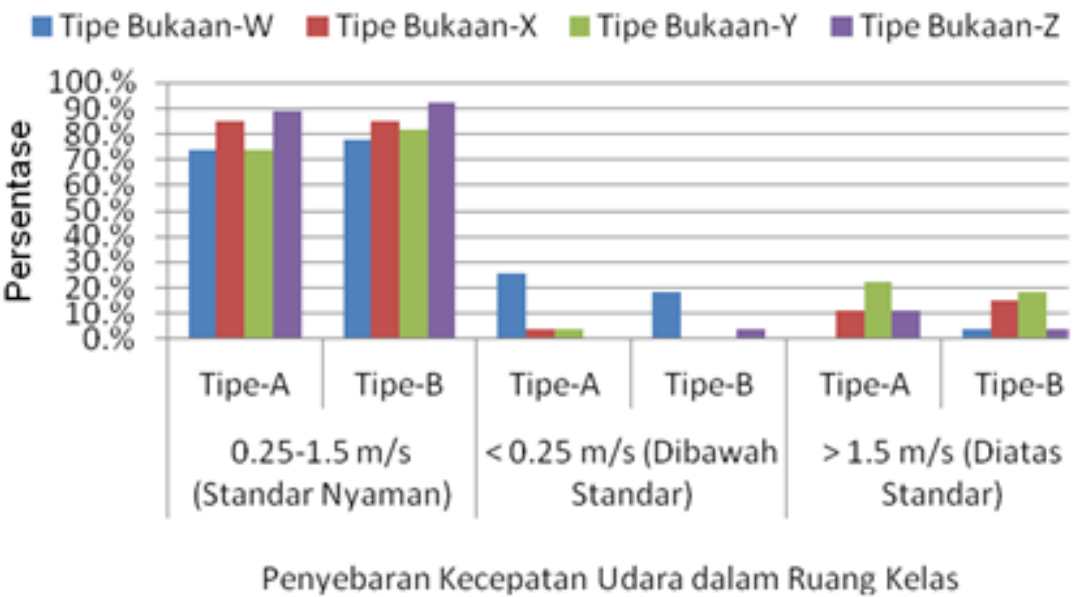

Gambar 3. Grafik Persentase Velocity RK dengan Beberapa Tipe Bukaan

(Sumber: Analisis penelitian, 2013) 


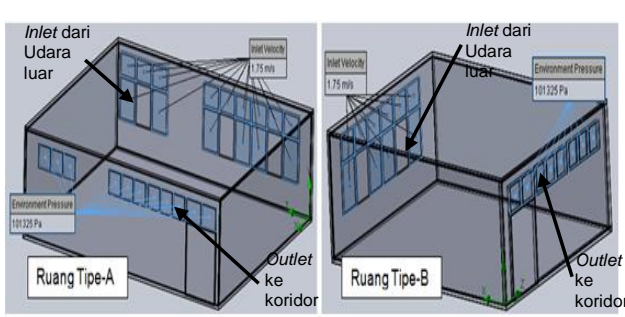

a

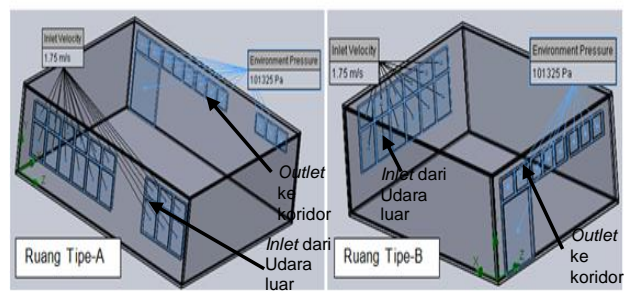

C
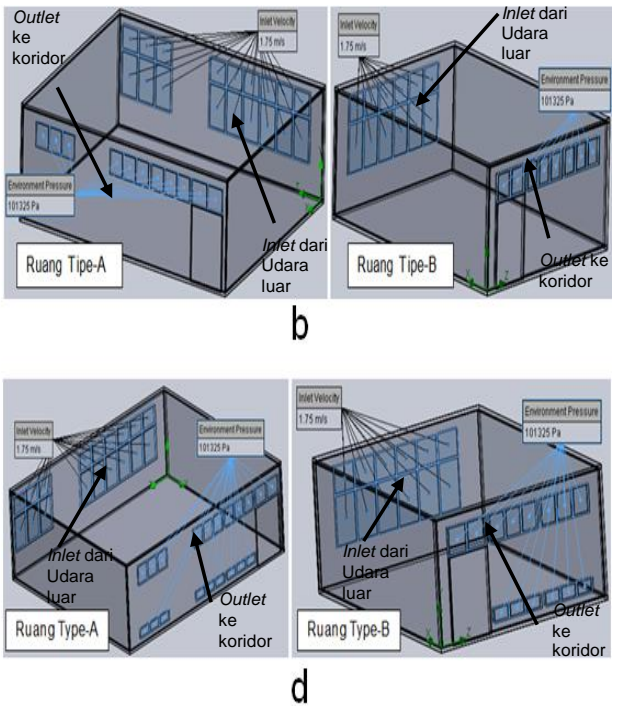

Gambar 4. Tipe Bukaan Ventilasi (Sumber: Simulasi CFD, 2013)

Pengaliran udara yang paling minim terjadi pada bukaan tipe-W. Terdapat $(74.07 \%)$ volume ruang yang memenuhi standar kecepatan aliran udara $(0.25 \mathrm{~m} / \mathrm{s}-1.5$ $\mathrm{m} / \mathrm{s}$ ) pada RK tipe-A dan (77.78\%) pada RK tipe-B. Persentase volume ruang yang aliran udaranya diatas standar $(>1.5 \mathrm{~m} / \mathrm{s})$ pada $R K$ tipe-A $(0.00 \%)$ dan RK tipe-B (3.70\%). Persentase volume ruang yang aliran udaranya dibawah standar $(<0.25 \mathrm{~m} / \mathrm{s})$ pada RK tipe-A (25.93\%), dan RK tipe-B (18.25\%).

Kecepatan udara outlet, pada hasil simulasi bukaan tipe-W (Gambar 4a) lebih kecil dibanding tipe-X (Gambar 4b), karena bukaan inlet tipe-X lebih luas dari tipe-W walau bukaan outlet-nya sama. Hal ini menyebabkan tekanan udara pada area sekitar outlet bukaan tipe-X lebih besar di banding tipe-W. Peningkatan tekanan udara ini yang mengakibatkan tekanan statis pada ruang bagian bawah bukaan mengakibatkan kecepatan udara yang lebih merata pada RK.

Jika tipe-X dibandingkan dengan tipe- $Y$ (Gambar 4c), maka bukaan tipe-Y memiliki kecepatan rata-rata pada outlet lebih kecil karena bukaan outlet-nya diperbesar (pintu kelas dianggap terbuka), sehingga terjadi tekanan udara lebih kecil karena udara dengan mudah keluar melalui pintu. Pembukaan pintu mengakibatkan kecepatan udara menjadi tidak merata. Area sekitar pintu memiliki kecepatan yang tinggi sedang area yang jauh dari pintu kecepatan udaranya rendah, sehingga formula ini merugikan dari sisi pemerataan kecepatan udara pada RK.

Bukaan tipe-W, tipe-X dan tipe-Y belum memberi efek kecepatan udara dalam ruang menjadi optimal sesuai standar kenyamanan. Bukaan tipe-X lebih baik dari tipe-W dan tipe$\mathrm{Y}$, kekurangannya jika kecepatan inlet ditingkatkan maka kecepatan pada titik ukur elevasi atas $(+1.5 \mathrm{~m})$ sudah melampaui standar, sedang masih ada ruang pada elevasi $(+0.5 \mathrm{~m})$ yang belum masuk standar. Hal ini disebabkan karena bukaan outlet yang keluar ke koridor terletak cukup tinggi, sehingga kecepatan udara dalam RK pada daerah sekitar dinding outlet di atas permukaan lantai mengalami penurunan.

Bukaan tipe-Z (Gambar 4d), luas bukaan ditambahkan setengah dari luas bovenlicht yang diletaknya $\pm 20 \mathrm{~cm}$ dari permukaan lantai dinding outlet, tujuannya untuk meningkatkan aliran angin bagian bawah ruangan. Hasilnya tekanan udara elevasi bawah berkurang, aliran udara melalui ventilasi bawah dapat meningkatkan kecepatan angin sekitar permukaan lantai. 


\section{Pengaruh Luas Ventilasi dan Velocity RK tipe-A dan tipe-B}

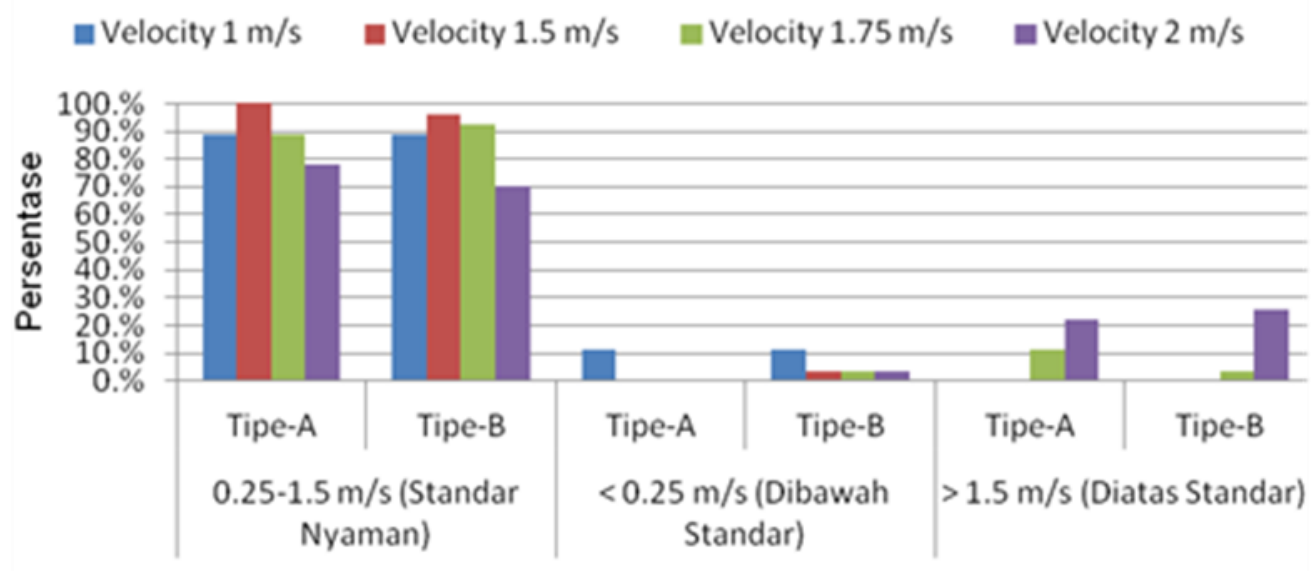

Penyebaran Kecepatan Udara dalam Ruang Kelas

Gambar 5. Grafik Persentase Velocity RK dengan parameter velocity inlet dan Tipe Bukaan

(Sumber: Analisis, 2013)

Gambar 5, memperlihatkan persentase kecepatan udara terbaik yang memenuhi standar kenyamanan termal terjadi jika velocity inlet $1.5 \mathrm{~m} / \mathrm{s}$ dengan bukaan tipe-Z. Terdapat (100\%) volume ruang yang memenuhi standar $(0.25 \mathrm{~m} / \mathrm{s}-1.5 \mathrm{~m} / \mathrm{s})$ pada RK tipe-A dan RK tipe-B (96.30\%). Persentase volume ruang yang aliran udaranya diatas standar $(>1.5 \mathrm{~m} / \mathrm{s})$ pada $R K$ tipe-A $(0.00 \%)$ dan RK tipe-B $(3.70 \%)$. Persentase volume ruang yang aliran udaranya dibawah standar $(<0.25 \mathrm{~m} / \mathrm{s})$ pada RK tipe-A (0.00\%), dan RK tipe-B (3.70\%).

Rekayasa sistem bukaan ventilasi pada RK tipe-A dan tipe-B, didapatkan perbaikan pemerataan kecepatan udara yang memenuhi standar kenyamanan termal $(0.25 \mathrm{~m} / \mathrm{s}-1.5$ $\mathrm{m} / \mathrm{s}$ ) yaitu RK tipe-A (74.07\%) dan RK tipe-B $(77.78 \%)$ untuk velocity inlet $1.75 \mathrm{~m} / \mathrm{s}$ pada kondisi eksisting. Dapat ditingkatkan menjadi $(100 \%)$ volume ruang yang aliran udaranya memenuhi standar pada RK Tipe-A dan RK Tipe-B (96.30\%) untuk velocity inlet $1.5 \mathrm{~m} / \mathrm{s}$, setelah rekayasa perbaikan sistem bukan inlet dan outlet (bukaan tipe-Z).

Hasil analisis didapat bahwa kecepatan udara inlet yang memberi efek aliran paling baik terhadap kenyamanan termal adalah velocity $1.5 \mathrm{~m} / \mathrm{s}$ karena bisa mencapai $100 \%$ volume ruang memenuhi standar aliran udara yang nyaman. Jika di bandingkan dengan kondisi eksisting aliran terbaik hanya bisa dicapai antara (77.78\%) hingga (85.19\%) dengan velocity inlet $2 \mathrm{~m} / \mathrm{s}$. Hal ini membuktikan bahwa rasio bukaan ventilasi yang baik dapat menurunkan kebutuhan kecepatan udara inlet untuk mencapai aliran udara yang optimal.

Hasil rekayasa Aliran Udara RK didapatkan luas bukaan ventilasi terbaik $21.60 \%$ dari luas lantai ruangan, dengan rincian luas bukaan Inlet $14.50 \%$ dan luas bukaan outlet $7.10 \%$.

\section{PEMBAHASAN}

Penelitian ini menemukan bahwa kondisi existing Ruang Kelas hanya dapat memberikan aliran udara nyaman sekitar $51.85 \%$ hingga $85.19 \%$ dari volume ruang. Upaya untuk meningkatkan aliran udara dengan pemberian velocity inlet yang lebih tinggi dari $2 \mathrm{~m} / \mathrm{s}$ justru mengakibatkan presentase kecepatan aliran udara diatas batas nyaman meningkat. Kondisi ini disebabkan oleh kurangnya luas bukaan inlet dan outlet, karena RK tipe-A hanya memiliki luas bukaan (16.63\%), dan RK tipe-B $(17.58 \%)$ dari luas lantai ruangan. Jika dibandingkan dengan penemuan Indrani (2008), yang mensyaratkan luasan ventilasi minimum $20 \%$ dari luas lantai ruangan, maka rasio luas bukaan RK masih kurang. 
Rekayasa dilakukan untuk meningkatkan aliran udara lebih optimal dengan menambah luas bukaan inlet, membuka jendela-jendela kaca mati agar dapat dilalui udara segar dari luar bangunan. Penambahan luas bukaan juga diterapkan pada dinding yang berfungsi sebagai outlet aliran keluar menuju koridor. Hasil rekayasa di dapatkan, penambahan luas bukan outlet yang terbaik jika letaknya $\pm 20 \mathrm{~cm}$ diatas lantai dengan luas setengah dari bukaan ventilasi diatasnya (bovenlicht). Sehingga didapatkan luas bukaan ventilasi terbaik untuk RK adalah $21.60 \%$ dari luas lantai ruangan, dengan rincian luas bukaan Inlet $14.50 \%$ dan luas bukaan outlet $7.10 \%$.

Penelitian ini juga didapatkan, bukaan Inlet yang lebih luas dibanding outlet akan meningkatkan velocity udara yang lebih merata pada ruangan. Udara yang akan keluar akan terhambat karena bukaan outlet kecil, sehingga akan meningkatkan tekanan statis pada area di bawah bukaan. Fariasi bukaan dapat diterapkan untuk meningkatkan kecepatan udara yang lebih merata dalam ruangan, namun harus diterapkan dengan cermat dan memenuhi syarat luasan total outlet lebih kecil dari Inlet, seperti yang diterapkan pada penelitian ini dengan memfariasikan bukaan outlet di bidang dinding bagian bawah.

\section{KESIMPULAN DAN SARAN}

Disimpulkan bahwa Ruang Kelas (RK) dengan kondisi existing hanya dapat memberikan kenyamanan sekitar 51.85\% hingga $85.19 \%$. Jika diberikan perbaikan terhadap luas bukaan ventilasi, maka tingkat kenyamanan RK menjadi $96.30 \%$ hingga $100 \%$.

Rekayasa untuk memaksimalkan aliran udara yang memenuhi standar nyaman termal pada RK dilakukan dengan memperluas bukaan ventilasi inlet dan outlet. Khusus untuk outlet penambahan bukaan diletakkan bagian bawah dinding, $\pm 20 \mathrm{~cm}$ dari permukaan lantai, sehingga rasio luasan bukaan ventilasi $(21.60 \%)$ dari luas lantai ruangan, dengan rincian luas bukaan Inlet (14.50\%) dan luas bukaan outlet $(7.10 \%)$.

Hasil penelitian, disarankan semua jendela pada posisi inlet harus terbuka tanpa adanya kaca mati, pintu sebaiknya di tutup pada saat ruang kelas digunakan.

\section{DAFTAR PUSTAKA}

Baharuddin, Ishak, M.T., Beddu, S., \& Yahya, M. (2012). Kenyamanan Termal Gedung Kuliah Bersama Kampus Baru Fakultas Teknik Universitas Hasanuddin. Semesta Arsitektur Nusantara SAN 1. Ref No: B.4.4. Malang: san121212.

Gratia, E., Bruyère, A., \& De Herde, A. (2004). How to use natural ventilation to cool narrow office buildings. Building and Environment, 39 (10): 1157-1170.

Indrani, H. (2008). Kinerja Ventilasi Pada Hunian Rumah Susun Dupak Bangunrejo Surabaya. Dimensi Interior, 6 (1): 9-23.

Kurnia, R., Effendy, S., Tursilowati, L. (2010). Identifikasi Kenyamanan Termal Bangunan (Studi Kasus: Ruang Kuliah Kampus IPB Baranang siang dan Darmaga Bogor). Jurnal Agromet, 24 (1): 14-22.

Liping, W., \& Hien, W.N. (2007). Applying Natural Ventilation for Thermal Comfort in Residential Buildings in Singapore. Architectural Science Review, 50 (3): 224-233.

Lippsmeier, G. (1994). Bangunan Tropis. (S. Nasution, Penerj.) Jakarta: Erlangga.

Mannan, (2007). Faktor kenyamanan dalam perancangan bangunan (kenyamanan suhu-termal pada bangunan). Jurnal Ichsan Gorontalo, 2 (1): 466-473

Sakti, W.B. (2013). Panduan Praktis Analisa CFD Menggunakan SolidWorks Flow Simulation. Jakarta: wbsakti.wordpreess.com 
Sugini. (2004). Pemaknaan Istilah-Istilah Kualitas Kenyamanan Thermal Ruang Dalam Kaitan Dengan Variabel Iklim Ruang. LOGIKA: 03-17.

Takahashi, I. (2005). Development of A Passive Cooling Strategy Using Double - Roofing System. The 2005 World Sustainable Building Confrence (hal. 91-96). Tokyo: SB05 Tokyo.

Talarosha, B. (2005). Menciptakan Kenyamanan Thermal Dalam Bangunan. Jurnal Sistem Teknik Industri, Volume 6: 148-158. 